\title{
A Simple Data Analysis Method for a Pumping Test with Skin and Wellbore Storage Effects
}

\author{
Chia-Shyun Chen ${ }^{*}$ and Chuan-Gui Lan \\ Graduate Institute of Applied Geology, National Central University, Chung-Li, Taiwan, ROC
}

Received 18 January 2008, accepted 16 May 2008

\begin{abstract}
In a pumping test conducted in a confined aquifer in northern Taiwan, drawdown in the observation well was subject to wellbore storage of its own and the combined effect of wellbore storage and skin of the nearby pumping well. For such a complicated pumping test condition, the appropriate well hydraulics solutions are complicated in mathematics and involve five unknown a priori parameters; namely, the aquifer transmissivity, the aquifer storage coefficient, the skin factor of the pumping well, and the wellbore storage coefficients of the pumping and observation wells. The conventional trial-and-error procedure for a simultaneous determination of these five parameters is not easy to apply. Here, a simple data analysis method is developed, which takes advantage of the late-time characteristics of drawdown data and the late-time asymptotic behavior of the appropriate well hydraulics solutions. As a result, some currently available graphic techniques are proven useful for the determination of these parameters. Validity of this approach is verified by the excellent agreement between the calculated drawdown using the appropriate well hydraulics solutions with the parameter estimates obtained from the field drawdown data.
\end{abstract}

Key words: Pumping test, Wellbore storage, Skin effect, Parameter estimation

Citation: Chen, C. S. and C. G. Lan, 2009: A simple data analysis method for a pumping test with skin and wellbore storage effects. Terr. Atmos. Ocean. Sci., 20, 557-562, doi: 10.3319/TAO.2008.05.16.01(Hy)

\section{INTRODUCTION}

Pumping test is commonly conducted using a pumping well and at least one nearby observation well. The pumping well is for the generation of a groundwater flow field, while the observation well is for the measurement of drawdown in response to pumping. Analyzing the time-drawdown variation in the observation well $\mathrm{h}(\mathrm{r}, \mathrm{t})$ with an appropriate well hydraulics model allows for the evaluation of the relevant aquifer parameters (all symbols defined in nomenclature unless otherwise noted). For a confined aquifer, transmissivity $\mathrm{T}$ and the storage coefficient $\mathrm{S}$ are the two parameters of primary concern. Their estimations normally make use of the Theis (1935) model, which is:

$h(r, t)=\frac{Q}{4 \pi T} W\left(\frac{r^{2} S}{4 T t}\right)$

where $\mathrm{W}(\cdot)$ is the well-known well function [e.g., see Theis

\footnotetext{
* Corresponding author

E-mail: chenchia@ncu.edu.tw
}

(1935); Schwartz and Zhang (2003)]. In Eq. (1), the radii of the pumping well, $\mathrm{r}_{\mathrm{w}}$, and the observation well, $\mathrm{r}_{\mathrm{o}}$, are not involved because they are assumed to be infinitesimally small. This simplification renders the Theis solution unsuitable for dealing with the skin effect and/or the wellbore storage effect; both of which are field occurrences.

In the pumping well, wellbore storage effect may occur in early pumping times, during which water withdrawn is not derived from the surrounding aquifer but from the water volume originally stored in the well casing (Papadopulos and Cooper 1967). When it occurs, early-time drawdown data from the pumping well, $\mathrm{h}_{\mathrm{w}}(\mathrm{t})$, is characteristic of a $45^{\circ}$ straight line on a logarithmic plot (Papadopulos and Cooper 1967; Fenske 1977; Streltsova 1988). Although wellbore storage in the pumping well only has an early-time influence on drawdown in nearby observation wells, neglecting it could result in overestimate of storage coefficient, S (e.g., Black and Kipp 1977; Mucha and Paulikova 1986; Narasimhan and Zhu 1993).

On the other hand, the skin effect is caused by drilling mud invading surrounding formations. In practice, drilling 
mud is frequently used during the drilling process to prevent boreholes from collapsing and to circulate drilling cuts. However, drilling mud can invade the formation and create a damaged zone of reduced permeability surrounding the borehole. This damaged zone induces extra head loss to groundwater flow. Due to difficulty in determining the actual thickness of the damaged zone, the damaged zone is usually simulated as an infinitesimally thin "skin", which nevertheless exerts a head drop on the wellbore surface - the skin effect. The skin effect is proportional to groundwater velocity across the wellbore surface and is represented by a dimensionless skin factor $S_{k}$. The larger the $S_{k}$ is the greater the head loss. For a badly skinned pumping well, $\mathrm{S}_{\mathrm{k}}$ can be as large as 18.57 (Chen and Chang 2002).

Both skin and wellbore storage can occur in a pumping well. Such a combined effect can influence drawdown variation in nearby observation wells (Agarwal et al. 1970; Chu et al. 1980; Park and Zhan 2002, 2003; Chen and Chang 2006), and neglecting it could result in serious overestimation of S and underestimation of T (Agarwal et al. 1970; Jargon 1976). For a confined, homogeneous and isotropic aquifer, the dimensionless drawdown solution of a fully penetrating pumping well subject to both wellbore storage and well skin is (Agarwal et al. 1970; Kabala 2001):

$$
\begin{aligned}
& \mathrm{h}_{\mathrm{wD}}(\tau)=\mathrm{L}^{-1} \\
& \left\langle\frac{\mathrm{p}}{\mathrm{p}\left\{\frac{\mathrm{p}}{2 \alpha_{\mathrm{w}}}[\sqrt{\mathrm{p}})+\mathrm{S}_{0}\left(\sqrt{\mathrm{p}} \mathrm{K}_{1}(\sqrt{\mathrm{p}})+\mathrm{S}_{\mathrm{k}} \sqrt{\mathrm{p}} \mathrm{K}_{1}(\sqrt{\mathrm{p}})\right]+\sqrt{\mathrm{p}} \mathrm{K}_{1}(\sqrt{\mathrm{p}})\right\}}\right\rangle
\end{aligned}
$$

where $\tau=\mathrm{Tt} /\left(\mathrm{r}_{\mathrm{w}}{ }^{2} \mathrm{~S}\right)$ is dimensionless time, and $\mathrm{p}$ the Laplace transform parameter with respect to $\tau$, and $\alpha_{\mathrm{w}}=$ $\mathrm{S}\left(\mathrm{r}_{\mathrm{w}} / \mathrm{r}_{\mathrm{wc}}\right)^{2}$ the wellbore storage coefficient of the pumping well. The symbol of $\mathrm{L}^{-1}$ denotes the Laplace inversion, which can be numerically carried out using the Stehfest (1970) method.

The skin effect of an observation well is generally not significant because the groundwater velocity in the vicinity of an observation well is usually small. However, every observation well needs a finite time to respond to a change in aquifer piezometric level as caused by pumping (Black and Kipp 1977; Fenske 1977). During this finite time, there is a delayed response in the observation well, referred to as wellbore storage of an observation well. Neglecting this wellbore storage can lead to an overestimation of $\mathrm{S}$ if the Theis solution is employed in data analysis (Black and Kipp 1977; Fenske 1977).

There was a pumping test in a confined aquifer, where drawdown in the observation well is subject to wellbore storage of its own as well as the combined effect of well skin and wellbore storage in a nearby pumping well. In this event, Eq. (2) is adequate for investigating the drawdown variation of $h_{w}(t)$. The drawdown solution of the observation well, however, can be derived in a straightforward manner as presented by (Moench 1997):

$$
\begin{aligned}
& \mathrm{h}_{\mathrm{oD}}(\rho, \tau)=\mathrm{L}^{-1} \\
& \left\langle\frac{\mathrm{K}_{0}(\rho \sqrt{\mathrm{p}}) /\left(1+\mathrm{W}_{\mathrm{D}} \mathrm{p}\right)}{\mathrm{p}\left\{\frac{\mathrm{p}}{2 \alpha_{\mathrm{w}}}\left[\mathrm{K}_{0}(\sqrt{\mathrm{p}})+\mathrm{S}_{\mathrm{K}} \sqrt{\mathrm{p}} \mathrm{K}_{1}(\sqrt{\mathrm{p}})\right]+\sqrt{\mathrm{p}} \mathrm{K}_{1}(\sqrt{\mathrm{p}})\right\}}\right\rangle
\end{aligned}
$$

where $\rho=r / r_{w}$ is dimensionless radial distance, and $\mathrm{W}_{\mathrm{D}}=$ $\pi \mathrm{br}_{\mathrm{oc}}^{2} /\left(\mathrm{r}_{\mathrm{w}}^{2} \mathrm{SF}\right)$ is a dimensionless coefficient reflecting the wellbore storage effect of the observation well. In $\mathrm{W}_{\mathrm{D}}, \mathrm{F}$ is a shape factor accounting for the influence of well geometry and hydrogeology on the flow rate across the well screen (see Hvorslev 1951). More detailed discussion of $F$ will be given below.

Equations (2) and (3) involve five unknown a priori parameters, $T, S, S_{k}, W_{D}$, and $\alpha_{w}$. Conventionally, these five parameters are estimated using a trial-and-error procedure, where drawdown is calculated with Eqs. (2) and (3) using different trial values of the five parameters until the results match measured drawdown. This approach, however, is not easy to apply because Eqs. (2) and (3) are complicated and the trial-and-error procedure is time consuming, especially for simultaneous determination of five parameters. Therefore, the purpose of this work is to develop a simple data analysis method to estimate the five parameters without using Eqs. (2) and (3). This method is based on the late-time asymptotic behavior of Eqs. (2) and (3) and the late-time characteristics of $h_{w}(t)$ and $h(r, t)$. As a result, some currently available graphic methods can be used to determine the parameters without a lengthy trialand-error procedure. Validity of this approach comes from excellent agreement between calculated drawdown using Eqs. (2) and (3) with the estimates obtained and measured results.

\section{THE PUMPING TEST}

A constant-rate pumping test was conducted in a confined Pleistocene age aquifer in Xinzhu County, northern Taiwan. Located 70 to $94 \mathrm{~m}$ below the ground surface $(\mathrm{b}=$ $24 \mathrm{~m}$ ), this aquifer is comprised of very fine sand and silt from 70 to $86 \mathrm{~m}$ and fine sand with traces of silty mud from 90 to $94 \mathrm{~m}$. Above the aquifer is a $5-\mathrm{m}$ thick layer of grey clay with traces of very fine sand. Below the aquifer is a layer of grey clay at least $2 \mathrm{~m}$ thick. Both the pumping and observation wells fully penetrate the aquifer with uniform 
radius; i.e., $r_{w} r_{w c}=7.62 \mathrm{~cm}$, and $r_{o}=r_{o c}=7.62 \mathrm{~cm}$. The tops of these two wells are at the same elevation of $31.970 \mathrm{~m}$ above the mean sea level, with respect to which drawdown in each well was measured. These wells were installed using the cable-tool percussion method, where heavy drilling mud was used for practical purposes. The pumping test began on 2006/12/27 and ran for 1277 minutes, during which time an electronic digital flow meter recorded a relatively constant pumping rate (less than $\pm 1.5 \%$ difference), $\mathrm{Q}=87 \mathrm{l} \mathrm{min}^{-1}$.

\section{DATA ANALYSIS METHOD}

It is known that the Laplace parameter $p$ is inversely related to $\tau$. By letting $\mathrm{p}$ approach zero, the late-time asymptotic formula of Eq. (3) can be obtained:

$\mathrm{h}_{\mathrm{oD}}(\rho, \tau)=\mathrm{L}^{-1}\left[\frac{\mathrm{K}_{0}(\rho \sqrt{\mathrm{p}})}{\mathrm{p}}\right]=\frac{1}{2} \mathrm{~W}\left(\frac{\mathrm{r}^{2} \mathrm{~S}}{4 \mathrm{Tt}}\right)$

where use is made of the small-argument asymptotic formulas of $\mathrm{K}_{0}(\cdot)$ and $\mathrm{K}_{1}(\cdot)$ in Abramowitz and Stegun (1970; p 375) and the Laplace inversion formula in Oberhettinger and (Badii 1973; p 338). As the late-time asymptotic behavior of Eq. (3) is the Theis solution, $\mathrm{T}$ and $\mathrm{S}$ can be determined by applying the well-known Cooper and Jacob (1946) method to late-time drawdown data from the observation well.

Before the determination of $\mathrm{T}$ and $\mathrm{S}$, however, it is important to know if the late-time drawdown data of $h(r, t)$ are not influenced by leakage from the top or bottom formations or recharge from the possible hydrogeologic boundary. As shown in Fig. 1, the variation of $h_{w}(t)$ in the first $18 \sim 20$ seconds exhibits a $45^{\circ}$ straight line, indicating the occurrence of wellbore storage in the pumping well. Therefore, only the late-time data of $h(r, t)$ match with the Theis curve. In Fig. 1, good late-time matching is observed, confirming little or no leakage/recharge in the pumping test. Thus the Cooper-Jacob (1946) method is appropriate for the determination of T and S.

The Cooper-Jacob (1946) method is demonstrated in Fig. 2, where $h(r, t)$ versus logarithmic time is plotted on semi-logarithmic paper. A straight-line relationship for the time-drawdown data is noted for late times. Its slope is $\Delta \mathrm{s}=$ $0.323 \mathrm{~m}$, so $\mathrm{T}$ is determined as:

$\mathrm{T}=\frac{0.183 \mathrm{Q}}{\Delta \mathrm{s}}=4.93 \times 10^{-2} \mathrm{~m}^{2} \min ^{-1}$

The straight line intersects the logarithmic time axis at $\mathrm{t}_{\mathrm{o}}=0.0342 \mathrm{~min}, \mathrm{so} \mathrm{S}$ is:

$\mathrm{S}=\frac{2.25 \mathrm{Tt}_{0}}{\mathrm{r}^{2}}=1.76 \times 10^{-4}$

The estimate of $\mathrm{S}$ is in the typical range of $10^{-5} \leqq \mathrm{~S} \leqq$ $10^{-3}$ for unconsolidated materials (e.g., Schwartz and Zhang 2003). The averaged hydraulic conductivity $\mathrm{K}$ of this aquifer can be deduced by noting $\mathrm{T}=\mathrm{Kb}$. As $\mathrm{b}=24 \mathrm{~m}, \mathrm{~K}=\mathrm{T} / \mathrm{b}=1.9$ $\times 10^{-3} \mathrm{~m} \mathrm{~min}^{-1}$, which corresponds to $\mathrm{K}$ of very sandy silt (Schwartz and Zhang 2003; p 79). Therefore, the values of $\mathrm{T}$ and $\mathrm{S}$ determined appear to be reasonable. Once $\mathrm{S}$ is known, $\alpha_{\mathrm{w}}$ can be evaluated using its definition; $\alpha_{\mathrm{w}}=$ $\mathrm{S}\left(\mathrm{r}_{\mathrm{w}} / \mathrm{r}_{\mathrm{wc}}\right)^{2}$. Since the pumping well has a uniform radius (that is, $\left.r_{w}=r_{w c}\right), \alpha_{w}=S=1.76 \times 10^{-4}$.

The determination of $\mathrm{W}_{\mathrm{D}}$ requires the knowledge of

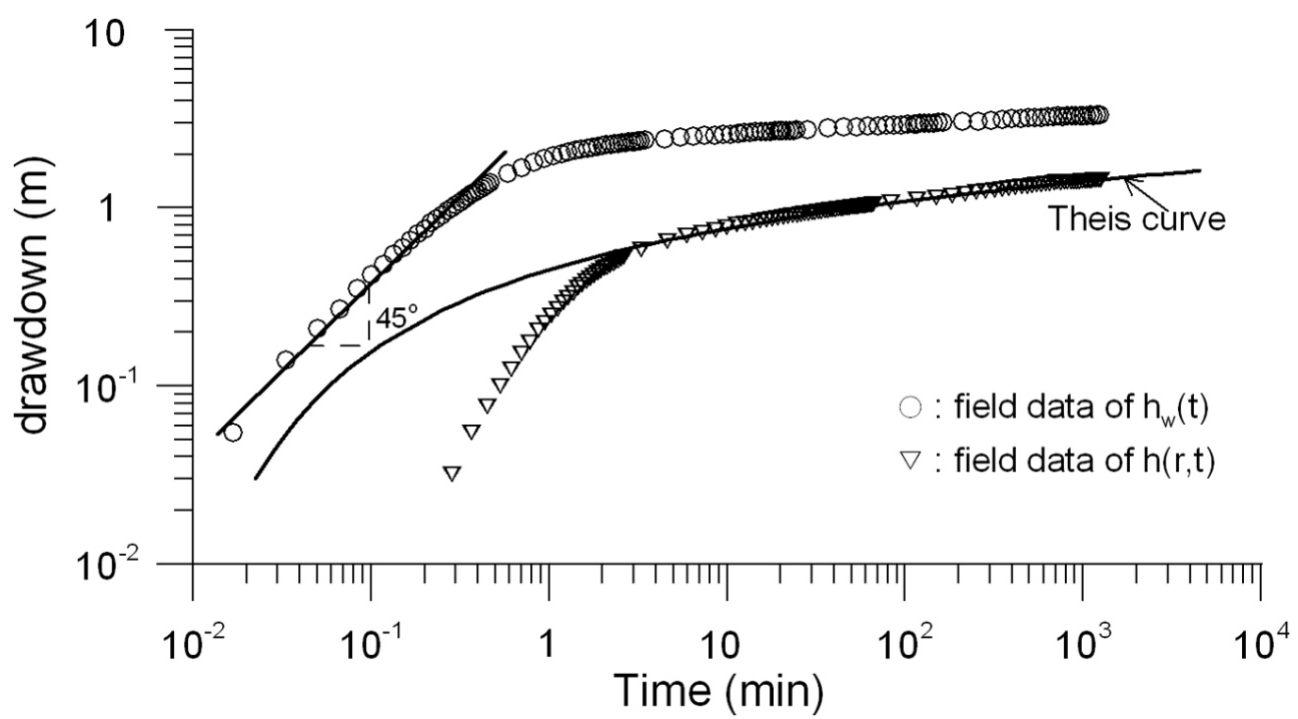

Fig. 1. The pumping-well and observation-well drawdown data plotted on logarithmic paper; the $45^{\circ}$ straight line of early-time $h_{w}(t)$ indicates wellbore storage effect in the pumping well. 


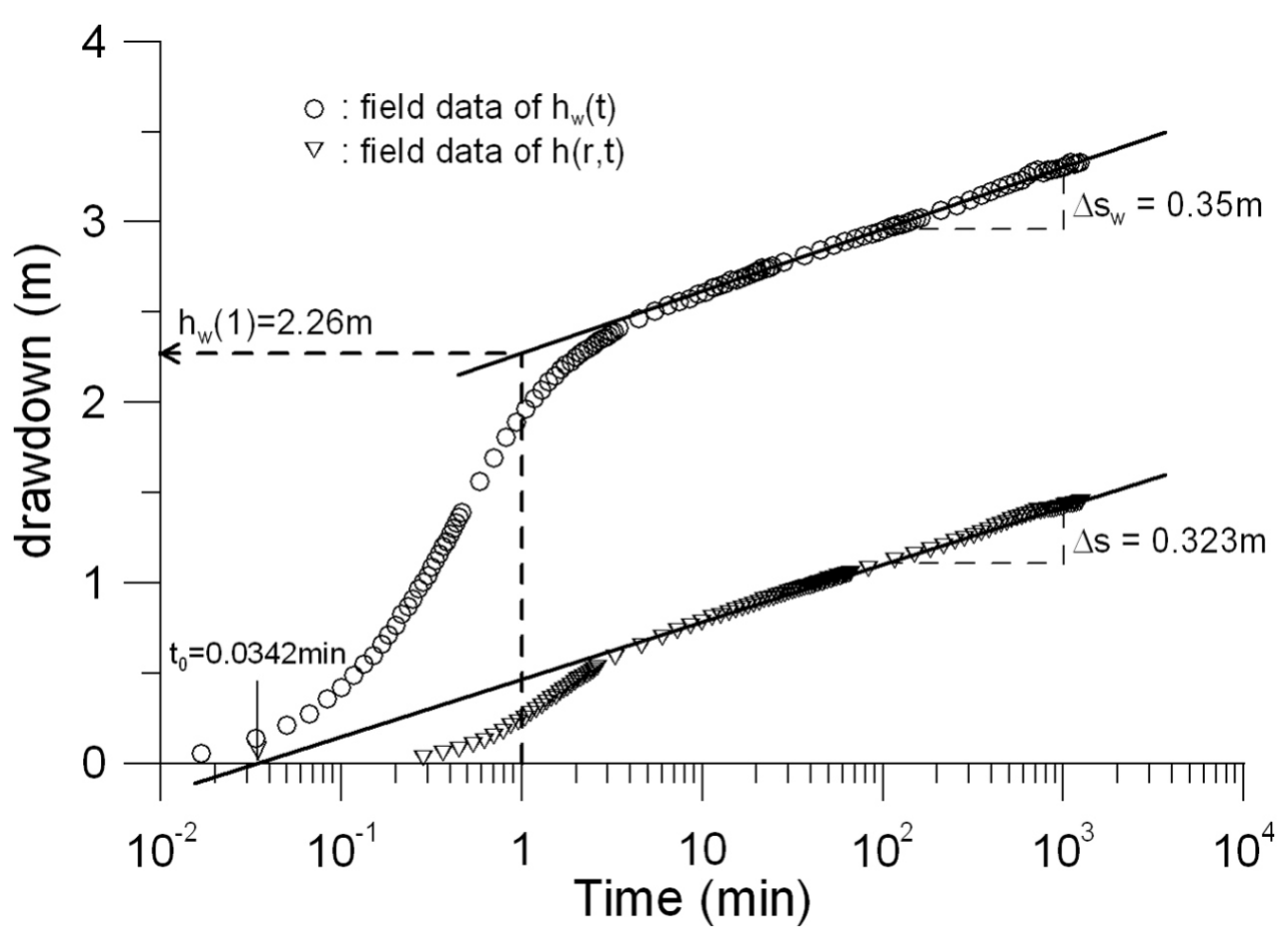

Fig. 2. The semilog plot of $h_{w}(t)$ and $h(r, t)$ for the determination of relevant parameters.

the shape factor, F. For a fully penetrating well in a confined aquifer, such as that used in the current study, $\mathrm{F}=$ $2 \pi \mathrm{b} / \ln \left(\mathrm{R}_{\mathrm{e}} / \mathrm{r}_{\mathrm{o}}\right.$ ) (Hvorslev 1951), where $\mathrm{R}_{\mathrm{e}}$ is the effective radius on which the flow from the observation well storage vanishes. The value of $R_{e}$ is normally taken as $200 r_{o}$ (US Dept. of Navy 1961; Butler 1998). As a result, $\mathrm{W}_{\mathrm{D}}=$ $2.65\left(\mathrm{r}_{\mathrm{oc}}^{2} / \mathrm{r}_{\mathrm{w}}^{2} \mathrm{~S}\right)$, where $\mathrm{r}_{\mathrm{oc}}$ is the radius of the well casing of the observation well. As $\mathrm{r}_{\mathrm{oc}}=\mathrm{r}_{\mathrm{w}}=7.62 \mathrm{~cm}, \mathrm{~W}_{\mathrm{D}}=1.51 \times 10^{4}$.

Now our analysis proceeds to determine $S_{k}$ based on the late-time asymptotic behavior of Eq. (2), which can be derived as:

$\mathrm{h}_{\mathrm{wD}}(\tau)=\mathrm{L}^{-1}\left[\frac{\mathrm{K}_{0}(\rho \sqrt{\mathrm{p}})+\mathrm{S}_{\mathrm{k}}}{\mathrm{p}}\right]=\frac{1}{2} \mathrm{~W}\left(\frac{\mathrm{r}^{2} \mathrm{~S}}{4 \mathrm{Tt}}\right)+\mathrm{S}_{\mathrm{k}}$

Equation (7) indicates that wellbore storage of the pumping well vanishes during late times while the steady-state head drop of the skin effect remains. Based on Eq. (7), Streltsova (1988) gives a graphic method for the determination of $S_{k}$ using the late-time drawdown data of $h_{w}(t)$ as:

$\mathrm{S}_{\mathrm{k}}=1.1513\left[\frac{\mathrm{h}_{\mathrm{w}}(1)}{\Delta \mathrm{s}_{\mathrm{w}}}-\log \frac{2.246 \mathrm{~T}_{\mathrm{w}}}{\mathrm{Sr}_{\mathrm{w}}{ }^{2}}\right]$

where $h_{w}(1)=2.26 \mathrm{~m}$ and is defined in Fig. 2 ; and $T_{w}$ is transmissivity determined using $\Delta \mathrm{s}_{\mathrm{w}}$; that is, $\mathrm{T}_{\mathrm{w}}=0.183 \mathrm{Q} / \Delta \mathrm{s}_{\mathrm{w}}$. As $\Delta \mathrm{s}_{\mathrm{w}}=0.35 \mathrm{~m}, \mathrm{~T}_{\mathrm{w}}=4.55 \times 10^{-2} \mathrm{~m}^{2} \mathrm{~min}^{-1}$. This $\mathrm{T}_{\mathrm{w}}$ value is close to $\mathrm{T}=4.93 \times 10^{-2} \mathrm{~m}^{2} \mathrm{~min}^{-1}$ as determined using $\mathrm{h}(\mathrm{r}, \mathrm{t})$. The relatively small difference $(8.5 \%)$ between $\mathrm{T}_{\mathrm{w}}$ and $\mathrm{T}$ is attributable to a slightly heterogeneous condition around the two wells, given that the measurement error of the pressure transducers is negligible. Then by Eq. (8), $\mathrm{S}_{\mathrm{k}}$ is calculated to be 1.68, which reflects mild well skin. This completes the determination of the five parameters.

\section{METHOD VALIDATION}

The validity of the simple data analysis method is checked by comparing the calculated drawdown using Eqs. (2) and (3) with the parameter estimates obtained to the measured drawdown of $h_{w}(t)$ and $h(r, t)$, respectively. The parameter values used are: $\mathrm{S}=\alpha_{\mathrm{w}}=1.76 \times 10^{-4}, \mathrm{~S}_{\mathrm{k}}=1.68$, and $\mathrm{W}_{\mathrm{D}}=$ $1.51 \times 10^{4} ; \mathrm{T}_{\mathrm{w}}=4.55 \times 10^{-2} \mathrm{~m}^{2} \mathrm{~min}^{-1}$ for Eq. (2) while $\mathrm{T}=$ $4.93 \times 10^{-2} \mathrm{~m}^{2} \mathrm{~min}^{-1}$ for Eq. (3). As shown in Fig. 3, the calculated and measured drawdown for both the pumping well and observation well are in excellent agreement, validating this data analysis method.

\section{CONCLUSION}

In a pumping test conducted in a confined aquifer, drawdown in the observation well is subject to wellbore storage of its own as well as the combined effect of wellbore storage and skin in the nearby pumping well. For such a 


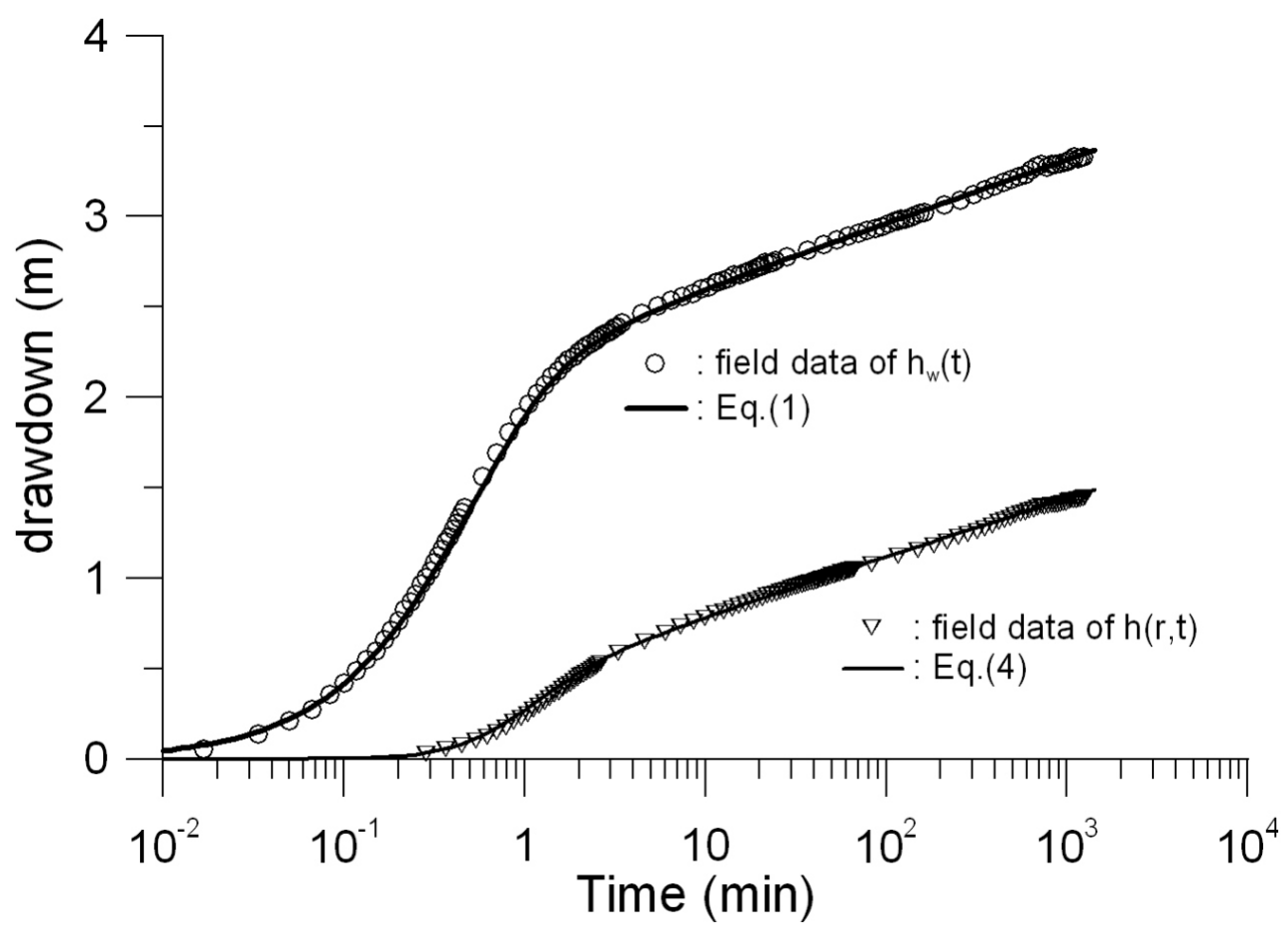

Fig. 3. Validation of the simple data analysis method by comparing the calculated and measured drawdown.

complicated pumping test condition, five unknown a priori parameters, $\mathrm{T}, \mathrm{S}, \alpha_{\mathrm{w}}, \mathrm{S}_{\mathrm{k}}$, and $\mathrm{W}_{\mathrm{D}}$, are involved. A simple data analysis method is developed, which takes advantage of the late-time asymptotic behavior of Eqs. (2) and (3) and the late-time characteristics of the pumping-well and observation-well drawdown data. As a result, some currently available graphic techniques are proven useful in determining the five relevant parameters. Validity of this approach is verified by the excellent agreement between the calculated drawdown using Eqs. (2) and (3) with the parameter estimates obtained and the field drawdown data. In order to apply this simple data analysis method, the pumping test should run long enough so that $h_{w}(t)$ and $h(r, t)$ can fully develop into straight lines on the semi-logarithmic plot. In this regard, it is worth mentioning that "cutting the pumping duration short for economic reasons is not justifiable because the cost of running the pumping test a few extra hours is low compared with the total costs of the test (Kruseman and de Ridder 1991)".

Acknowledgement This work is partly supported by NSC95-2116-M-008-010 and MOEAWRA0950413. We appreciate suggestions made for field safety and management by Chiu Tai.

\section{REFERENCES}

Abramowitz, M. and I. A. Stegun, 1970: Handbook of Mathematical Functions, Dover Publications, Inc. New York.
Agarwal, R. G., R. Al-Hussainy, and H. J. Ramey Jr., 1970: An investigation of wellbore storage and skin effect in unsteady liquid flow: I. Analytical treatment. Trans. Soc. Pet. Eng. AIME, 249, 279-290.

Black, J. H. and K. L. Kipp, 1977: Observation well response time and its effect upon aquifer test results. J. Hydrol., 34, 297-306, doi: 10.1016/0022-1694(77)90137-8. [Link]

Butler, J. J. Jr., 1998: The Design, Performance, and Analysis of Slug Tests, Boca Raton, Lewis Publishers, Florida, USA.

Chen, C. S. and C. C. Chang, 2002: Use of cumulative volume of constant-head injection test to estimate aquifer parameters with skin effects: Field experiment and data analysis. Water Resour. Res., 38, 1056, doi: 10.1029/2001 WR000300. [Link]

Chen, C. S. and C. C. Chang, 2006: Theoretical evaluation of non-uniform skin effect on aquifer response under constant rate pumping. J. Hydrol., 317, 190-201, doi: 10.1016/ j.jhydrol.2005.05.017. [Link]

Chu, W. C., J. Garcia-Rivera, and R. Raghavan, 1980: Analysis of interference test data influenced by wellbore storage and skin at the flowing well. J. Pet. Tech., 32, 171-178, doi: 10.2118/8029-PA. [Link]

Cooper, H. H., Jr. and C. E. Jacob, 1946: Generalized graphical method for evaluating formation constants and summarizing well-field history. Trans. $A G U, \mathbf{2 7}$, 526-534.

Fenske, P. R., 1977: Radial flow with discharging-well and observation-well storage. J. Hydrol., 32, 87-96, doi: 10.1016/ 0022-1694(77)90120-2. [Link]

Hvorslev, M. J., 1951: Time lag and soil permeability in ground- 
water observations. Corps of Engineers, US Waterways Experimental Station, Vicksburg, Mississippi, USA, Buttetin 36.

Jargon, J. R., 1976: Effect of wellbore storage and wellbore damage at the active well on interference test analysis. $J$. Pet. Tech., 28, 851-858, doi: 10.2118/5795-PA. [Link]

Kabala, Z. J., 2001: Sensitivity analysis of a pumping test on a well with wellbore storage and skin. Adv. Water Resour., 24, 483-504, doi: 10.1016/S0309-1708(00)00051-8. [Link]

Kruseman, G. P. and N. A. de Ridder, 1991: Analysis and Evaluation of Pumping Test Data. ILRI publication No. 47, $2^{\text {nd }}$ Edition, Wageningen, The Netherlands.

Moench, A. F., 1997: Flow to a well of finite diameter in a homogeneous, anisotropic water table aquifer. Water Resour. Res., 33, 1397-1407, doi: 10.1029/97WR00651. [Link]

Mucha, I. and E., Paulikova, 1986: Pumping test using large diameter production and observation wells. J. Hydrol., 89, 157-164, doi: 10.1016/0022-1694(86)90149-6. [Link]

Narasimhan, T. N. and M. Zhu, 1993: Transient flow of water to a well in an unconfined aquifer: Applicability of some conceptual models. Water Resour. Res., 29, 179-191, doi: 10.1029/92WR01959. [Link]

Oberhettinger, F. and L. Badii, 1973: Tables of Laplace Transforms, Springer-Verlag, Berlin Heidelberg, New York.

Papadopulos, I. S. and H. H. Cooper, 1967: Drawdown in a well of large diameter well. Water Resour. Res., 3, 241-244, doi: 10.1029/WR003i001p00241. [Link]

Park, E. and H. Zhan, 2002: Hydraulics of a finite-diameter horizontal well with wellbore storage and skin effect. $A d v$. Water Res., 25, 389-400, doi: 10.1016/S0309-1708(02) 00011-8. [Link]

Park, E. and H. Zhan, 2003: Hydraulics of horizontal wells in shallow aquifer systems. J. Hydrol., 281, 147-158, doi: 10.1016/S0022-1694(03)00206-3. [Link]

Schwartz, F. W. and H. Zhang, 2003: Fundamentals of Ground Water, John Wiley \& Sons, Inc., 583 pp.

Stehfest, H., 1970: Algorithm 368 numerical inversion of Laplace transforms [D5]. Commun. ACM, 13, 47-49, doi: 10.1145/361953.361969. [Link]
Streltsova, T. D., 1988: Well Testing in Heterogeneous Formations, Wiley, New York, 413 pp.

Theis, C. V., 1935: The relation between the lowering of the piezometric surface and the rate and duration of discharge of a well using Ground-Water Storage. Trans. $A G U, \mathbf{1 6}$, 519-524.

U. S. Dept. of Navy, Bureau of Yards and Docks, 1961: Design Manual: Soil Mechanics, Foundations, and Earth Structures, DM-7, Chap. 4.

\section{NOMENCLATURE}

$\mathrm{b}=$ aquifer thickness, (L).

$\mathrm{F}=2 \pi \mathrm{b} / \ln \left(\mathrm{R}_{\mathrm{e}} / \mathrm{r}_{\mathrm{o}}\right)$, the dimensionless shape factor.

$\mathrm{h}_{\mathrm{w}}(\mathrm{t})=$ pumping-well drawdown, $(\mathrm{L})$.

$h(r, t)=$ drawdown in the aquifer at distance $r,(L)$.

$\mathrm{K}_{0}(\mathrm{x}), \mathrm{K}_{1}(\mathrm{x})=$ modified Bessel functions of the second kind with order 0 and 1 , respectively.

$\mathrm{p}=$ Laplace transform parameter of $\tau$.

$\mathrm{Q}=$ constant pumping rate, $\left(\mathrm{L}^{3} \mathrm{t}^{-1}\right)$.

$\mathrm{r}=$ distance between the pumping well and the observation well, (L).

$\mathrm{r}_{\mathrm{w}}, \mathrm{r}_{\mathrm{wc}}=$ radius of well screen and casing of the pumping well, respectively, (L).

$\mathrm{r}_{\mathrm{o}}, \mathrm{r}_{\mathrm{oc}}=$ radius of well screen and casing of the observation well, respectively, (L).

$\mathrm{R}_{\mathrm{e}}=$ effective radius, $(\mathrm{L})$.

$\mathrm{S}=$ dimensionless storage coefficient.

$\mathrm{S}_{\mathrm{k}}=$ dimensionless skin factor of the pumping well.

$\mathrm{T}, \mathrm{T}_{\mathrm{w}}=$ transmissivity determined using $\mathrm{h}(\mathrm{r}, \mathrm{t})$ and $\mathrm{h}_{\mathrm{w}}(\mathrm{t})$, respectively, $\left(\mathrm{L}^{2} \mathrm{t}^{-1}\right)$.

$\alpha_{\mathrm{w}}=\mathrm{S}\left(\mathrm{r}_{\mathrm{w}} / \mathrm{r}_{\mathrm{wc}}\right)^{2}$, wellbore storage coefficient of the pumping well.

$\rho=r / r_{w}$, dimensionless radial distance.

$\tau=\mathrm{Tt} / \mathrm{Sr}_{\mathrm{w}}{ }^{2}$, dimensionless time.

$\Delta \mathrm{s}, \Delta \mathrm{s}_{\mathrm{w}}=$ slope of the straight lines of large time $\mathrm{h}(\mathrm{r}, \mathrm{t})$ and large time $h_{w}(t)$, respectively, on semi-logarithmic plot. $\mathrm{W}_{\mathrm{D}}=\pi \mathrm{br} \mathrm{oc}_{\mathrm{oc}}^{2} /\left(\mathrm{r}_{\mathrm{w}}^{2} \mathrm{SF}\right)$, the dimensionless coefficient in Eq. (3). 